\title{
Designing an Energy-Efficient Building in a Context of Helping Self-Build
}

\author{
Emmanuel Ouédraogo ${ }^{1, *}$, Ousmane Coulibaly ${ }^{2}$, Kossi Bouto Imbga $^{2}$, \\ Ouamnoaga Alain Gilbert Koala ${ }^{3}$, Abdoulaye Ouédraogo ${ }^{1}$, Florent Pèlèga Kieno ${ }^{1}$, \\ Diendonné Joseph Bathiebo ${ }^{1}$ \\ ${ }^{1}$ Department of Physics and Chemistry, Formation and Research Unit in Sciences and Technologies, University of Ouahigouya, Ouahigouya, \\ Burkina Faso \\ ${ }^{2}$ Department of Physics, Formation and Research Unit in Exact and Applied Sciences, University Ouaga 1 Pr Joseph KI-ZERBO, \\ Ouagadougou, Burkina Faso \\ ${ }^{3}$ Bioclimatic Architecture Agency, Ouagadougou, Burkina Faso
}

\section{Email address:}

ouedem7@gmail.com (E. Ouédraogo), coulous2005@yahoo.fr(O. Coulibaly), kossiimbga@yahoo.fr (K. B. Imbga), askia366@yahoo.fr(A. Ouédraogo), koalalain@yahoo.fr(O. A. G. Koala), kienoflorent@gmail.com (F. P. Kieno), djbathiebo@gmail.com (D. J. Bathiebo)

${ }^{*}$ Corresponding author

\section{To cite this article:}

Emmanuel Ouédraogo, Ousmane Coulibaly, Kossi Bouto Imbga, Ouamnoaga Alain Gilbert Koala, Abdoulaye Ouédraogo, Florent Pèlèga Kieno, Diendonné Joseph Bathiebo. Designing an Energy-Efficient Building in a Context of Helping Self-Build. American Journal of Energy Engineering. Vol. 6, No. 3, 2018, pp. 29-37. doi: 10.11648/j.ajee.20180603.12

Received: October 22, 2018; Accepted: November 7, 2018; Published: November 30, 2018

\begin{abstract}
This article presents a study of the performance of a typical building with walls made of local materials. The work consisted in evaluating the thermal comfort in a building built of cut lateritic blocks. This study is a contribution to the development of thermal regulations in Burkina Faso, a country with a dry tropical climate. It will also contribute to solve housing problems in rural and peri-urban areas through the construction of decent housing. The proposed standard building was modelled using TRNSYS software and the simulation determined the atmosphere (relative air temperatures and humidity) in the building's rooms. Air temperature values range from $25.5^{\circ} \mathrm{C}$ to $31.6^{\circ} \mathrm{C}$ in the Yako side block rooms. A reduction in the temperature and relative humidity values of the internal air and a high damping of the internal thermal amplitudes have been observed. However, the temperature values have shown that thermal comfort is not achieved in the rooms during the hot periods of the year. This comfort is improved with the use of Reo blocks, because there is a decrease from 1.0 to $1.5^{\circ} \mathrm{C}$ in the monthly average values of the internal temperature. However, comfort deteriorates when the walls are made of BoboDioulasso lateritic bricks due to the minimum increase in the average temperature of $0.5^{\circ} \mathrm{C}$. The values of energy consumption ratios, thermal phase shift times and damping factors show that the building has good energy performance.
\end{abstract}

Keywords: Air Temperature, Thermal Comfort, Energy Saving, Decrement Factor and Time Lag

\section{Introduction}

Energy consumed in the building sector represents about $30 \%$ of the world's energy consumption. This sector is therefore a key target for improving energy efficiency [1]. The improvement of this efficiency requires the development of energy efficiency codes, which aim above all to provide answers to a triple problem [1]. First, there is the absence of energy consideration problem in the design and management of buildings in developing countries. Then; the one related to the control of energy expenditure following the fluctuation of oil and gas costs on the international market. And finally, there has the duty to reduce greenhouse gases in the construction sector. In addition, energy savings have also become essential at the administrative level. This has been the case since the proper management of national resources 
in each country requires public services to honour their commitments to electricity, water and telephone companies, to name but a few. As a result, for many countries, electricity bills for air conditioning have become unsustainable. It is estimated that the energy consumption of public and private buildings and the tertiary sector in sub-Saharan Africa amounts to between 250 and $450 \mathrm{kWh} / \mathrm{m}^{2}$ airconditioned/year depending on the number of floors [2] In Burkina Faso, buildings have been designed to date without energy constraints. This results in very high costs, especially for operators who are not aware of rational energy use. Thus, the energy consumption of public sector buildings, particularly for the operation of air conditioning equipment, is estimated at 30,000 MWh/year, which corresponds to an estimated financial cost of CFA F 3.4 billion/year [3]. An analysis of the conditions under which electricity is used in public and private buildings revealed shortcomings [3]. These shortcomings are due to the lack of a management and maintenance policy for energy equipment, the low general qualification of maintenance staff and the "energy-intensive" nature of most buildings. This energetic character is linked to the architectural and functional design problems of these buildings. Halawa et al [4] have shown that building envelopes that separate the indoor environment from outdoor environments, and in particular building facades, play an important role in saving energy in buildings. The energy and thermal performance of building façades depends on the various possible designs and technical configurations, particularly in hot and humid climates. Architects and engineers should take into account, from the design stage, the ultimate impacts of building physics on overall energy performance and indoor comfort conditions. Mirrahimi et al [5] have shown that energy consumption can be significantly reduced by adopting energy efficiency strategies in such buildings. Due to environmental concerns and high energy costs in recent years, there has been renewed interest in energy efficiency in buildings. A recent study in Malaysia indicates that residential buildings consume about $19 \%$ of the total energy consumed in Malaysian sectors. One of the most potential strategies applied to the building envelope in hot and humid tropical regions is the passive design method and applies to the building envelope in these regions. AbreuHarbich et al [6] have shown that the use of mechanical systems that cool environments such as air conditioners to reduce indoor air temperature can increase the building's energy consumption by about $50 \%$. The work of Dabe et al [7] has highlighted the very important role of the building profile in controlling the direct penetration of daylight into the interior space of a building. This study showed that excessive penetration can cause visual and thermal discomfort for occupants in the Nagpur region of central India, which has a hot and dry climate. The work of Ren et al [8] assesses the impact of thermal comfort criteria by lowering the acceptability limits of cooling energy requirements for Australian residential buildings in current and future climates (with an assumed global warming of $2^{\circ} \mathrm{C}$ ), using building simulations using three different types (light, heavy and combined constructions). The results show that in future climates, relaxing the criteria for thermal comfort by lowering the limits of acceptability. They also found that, for all climates, the relaxation of the acceptability limits from $90 \%$ to $80 \%$ had a greater impact than that of $80 \%$ to $70 \%$. By relaxing the limits of acceptability, energy consumption for space cooling can be minimized in tropical and subtropical areas for lightweight, high-performance houses. Savings could be achieved in the building sector if the architectural design and choice of building materials took into account the thermal behaviour of buildings in order to minimize air conditioning and lighting requirements. David Y. K. Toguyeni et al [9] showed that the clay-straw mixture reduces air conditioning requirements compared to the clay wall by about $8 \%$. Concerning the roof, the study showed that $1.5 \mathrm{~cm}$ thick insulation (common situation) results in savings of around $8.3 \%$ (white wood) to $12.1 \%$ (insulating panel) on air conditioning loads. The results of Compaore et al [10] show that local building materials represent a good alternative for the search for energy efficiency in buildings. Compaore et al [11] also showed that air temperatures inside habitats with walls made of local materials (earth materials) are lower than those of modern habitats (cement blocks). This study proposes to assess the thermal performance of a building. The building is type F2 in cut lateritic blocks. It is intended to be scalable and must be accessible to as many people as possible. The cut lateritic blocks come from three quarries and have good thermal performance [12].

\section{Methodology}

\subsection{Bioclimatic Design of an F2 building}

Bioclimatic architecture uses local potential (climates, materials, labour, etc.) to recreate an indoor climate that respects everyone's comfort by adapting to the climatological variations of the place. It therefore inevitably requires an excellent knowledge of its environment. Burkina Faso has a dry tropical climate characterized by two warm seasons with high air temperature values (on average $39^{\circ} \mathrm{C}$ ) [13]. For the design of a bioclimatic building, local building materials have been used, in this case they are characterized by cut laterite blocks (BLT). Their costs are lower and a more suitable workforce is available for both construction and maintenance. Lateritic brick (BLT) constructions also make it possible to accumulate strong solar radiation, thus limiting the risk of overheating of the premises because they have better thermal properties than cement block bricks $[12,13]$. Research by Lawane et al [14] has shown that lateritic blocks have good mechanical properties for use in construction. The roof of the building is insulated with polystyrene, which limits the heat input through the roof [9]. With regard to the management of solar radiation, the largest glazed surfaces are oriented towards the north, protecting them from direct radiation. Sunshades are installed in the south-facing windows (south-facing facades). A light colour with a low absorption coefficient was used for the internal coating of the 
walls. Finally, natural ventilation is used to the best of its ability. This ventilation is at the heart of bioclimatic design in hot climates. It allows thermal loads to be evacuated during the night when outdoor air temperature values are low, so it is important to use the cold strategy of protecting yourself from solar gains, adopting passive cooling solutions using natural ventilation or humidification and limiting internal loads. All these design principles have allowed us to arrive at the following architectural plan:

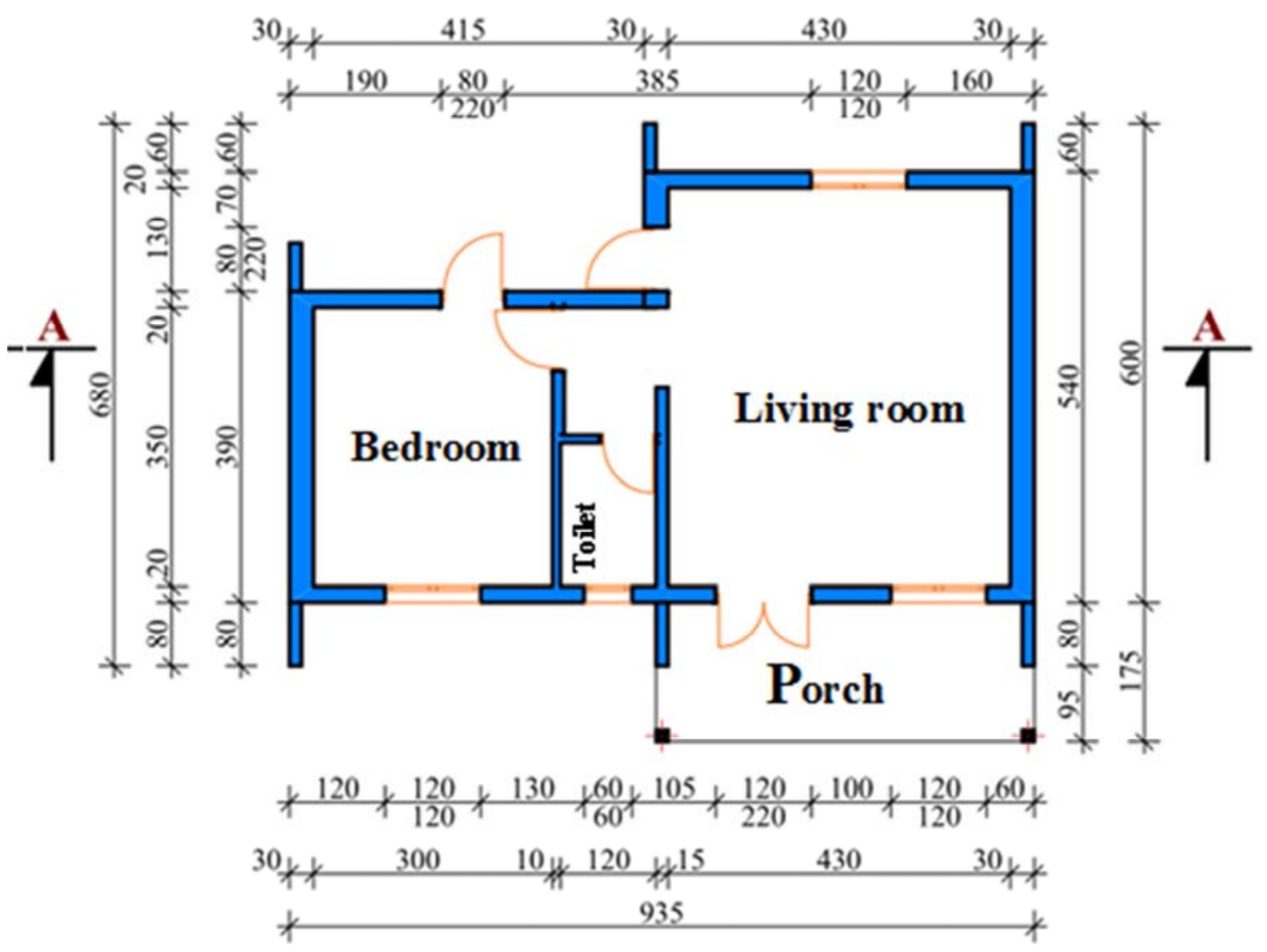

Figure 1. Level plan.

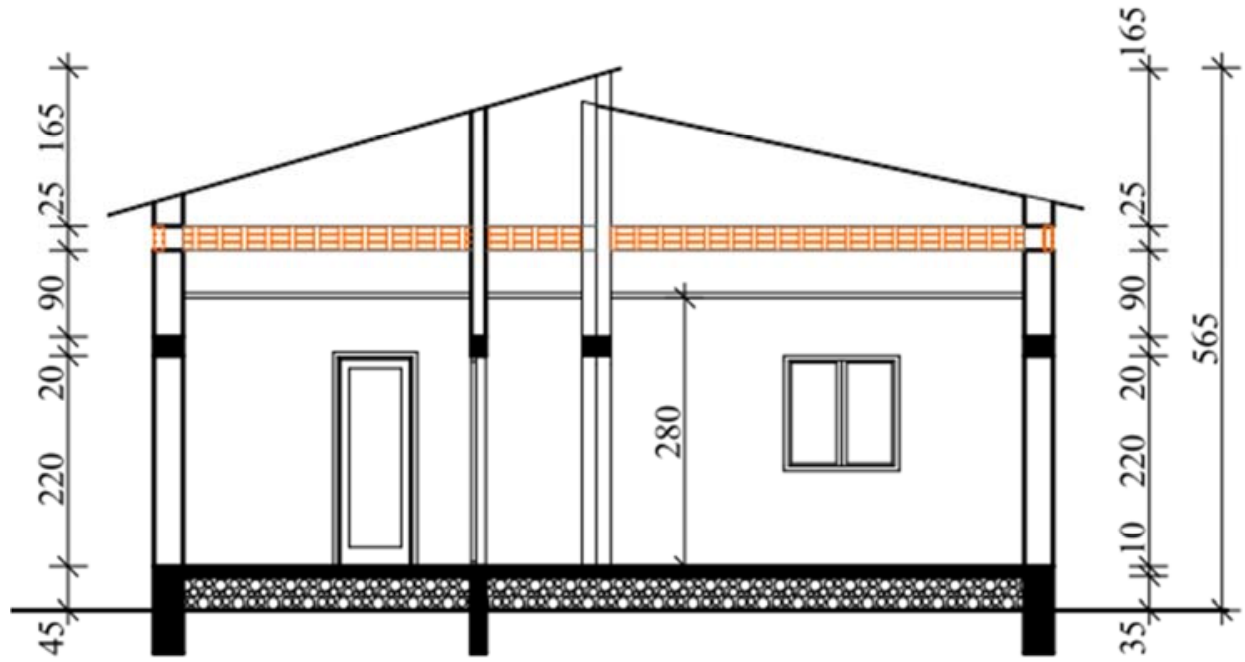

Figure 2. Section A. A. 


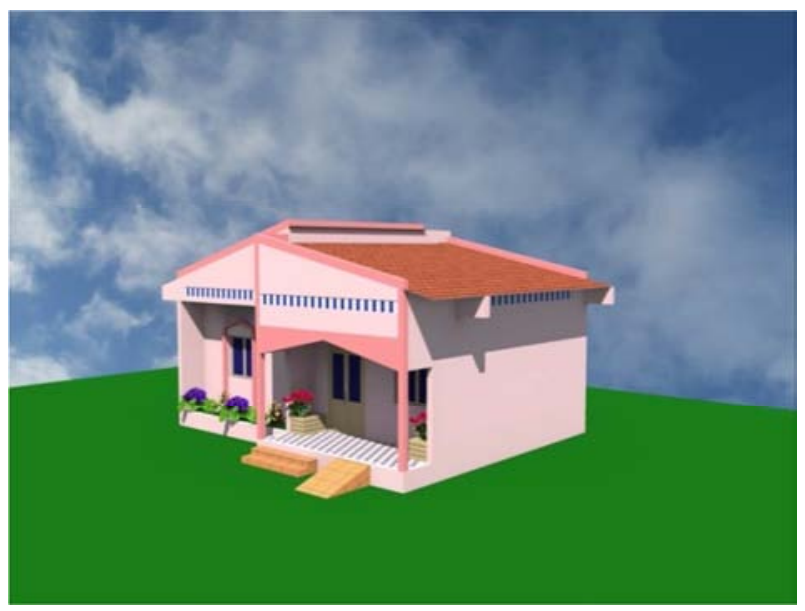

Figure 3. 3D Building Plan.

- The south walls are made of $20 \mathrm{~cm}$ thick lateritic brick and $05 \mathrm{~cm}$ of thermal insulation (polystyrene).

- The west, east and north walls are made of $20 \mathrm{~cm}$ thick cut lateritic bricks.

- Lateritic bricks are used from the three (03) quarries whose thermo-physical properties are represented in Table 1.

Table 1. Thermal physical properties of cut laterite blocks (BLT) [12].

\begin{tabular}{llll}
\hline Thermal-physical properties & Bobo-Dioulasso lateritic block (BLT_Bobo) & Reo lateritic block (BLT_Reo) & Yako lateritic block (BLT_Yako) \\
\hline Thermal conductivity $\left(\mathrm{W} \cdot \mathrm{m}^{-1} \cdot \mathrm{K}^{-1}\right)$ & $0.577 \pm 0.014$ & $0.444 \pm 0.012$ & $0.469 \pm 0.011$ \\
Density $\left(\mathrm{kg} \cdot \mathrm{m}^{-3}\right)$ & $1892.293 \pm 47.305$ & $1813.024 \pm 45.327$ & $1853.319 \pm 46.323$ \\
Thermal capacity $\left(\mathrm{J} \cdot \mathrm{kg}^{-1} \cdot \mathrm{K}^{-1}\right)$ & $1027.853 \pm 25.698$ & $1143.945 \pm 28.569$ & $982.562 \pm 24.565$ \\
Thermal diffusivity $\left(10^{-7} \mathrm{~m}^{2} \cdot \mathrm{s}^{-1}\right)$ & $2.973 \pm 0.074$ & $2.145 \pm 0.053$ & $2.783 \pm 0.070$ \\
Thermal effusivity $\left(\mathrm{J} \cdot \mathrm{s}^{-1 / 2} \mathrm{~m}^{-2} \cdot \mathrm{K}^{-1}\right)$ & $1059.363 \pm 26.483$ & $958.676 \pm 23.967$ & $889.043 \pm 22.215$ \\
\hline
\end{tabular}

\subsection{Assembly of Modules Under TRNSYS}

The building plan is describedusing TRNSYS' multi-zone model (TYPE 56)[15]. In summary, the assembly shown in Figure 4 includes:

1. Climate data entry. At this level the files used are the typical meteorological year for the city of Ouagadougou [16, 17].

2. The calculation of short and long wavelength radiation in different directions, the equivalent temperature of the celestial vault, psychrometrics parameters and ground temperature.

3. Calculation of the thermal loads of the building through the TRNSYS multi-zone building model type 56.

4. Finally, there is the data output through the integrator and the printer.

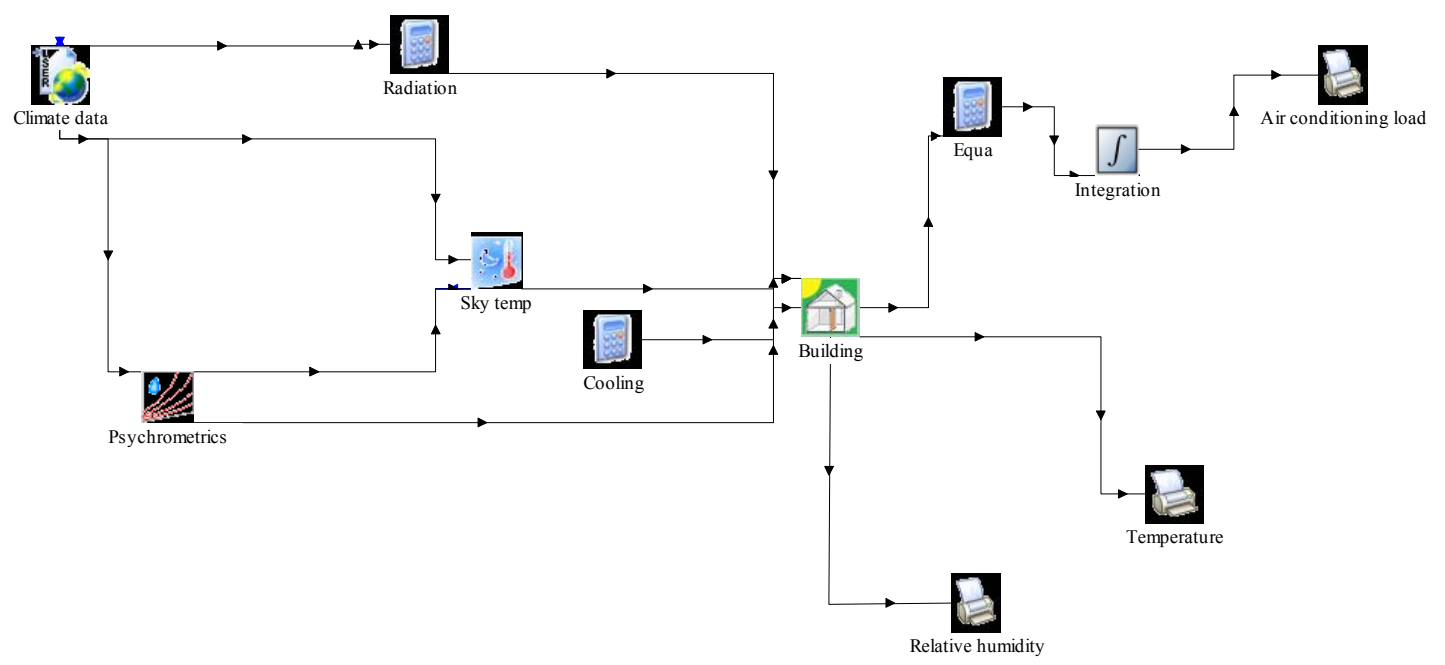

Figure 4. Assembly of modules for building description in TRNSYS.

The values of the simulated internal temperatures and those of the external air temperatures were used to evaluate the thermal phase shift time and the damping factor.
The thermal phase shift time is the time required for the indoor temperature to reach its maximum from the time the outdoor temperature peak occurs. It evolves with the inertia 
of the building and is determined by equation 1:

$$
\varphi=t_{T_{i n, \max }}-t_{T_{e x, \max }}
$$

Where: $\phi(h)$ is the thermal phase shift, $t_{T i n, \max }$ and $t_{T e x, \max }$ are the times at which the internal and external temperature peaks are reached respectively.

The damping factor is the ratio of the amplitudes of the indoor temperature and the outdoor temperature. The lower the damping factor, the more the indoor temperatures are damped. It is determined by equation 2 :

$$
f=\frac{\Delta T_{i n}}{\Delta T_{e x}}
$$

With $\Delta T_{i n}$ : internal temperature amplitude and $\Delta T_{e x}$ : external temperature amplitude.

These properties of the building envelope are important because they allow the internal environment to be characterized. They are evaluated according to internal and external temperatures and provide information on the behaviour of the envelopes.
To also evaluate the energy consumption performance of a building due to air conditioning. The overall efficiency is estimated by using energy consumption per unit of floor space. This energy consumption ratio $R\left(k W h \cdot a n^{-1} \cdot m^{-2}\right)$ is determined by equation 3 :

$$
R=\frac{E}{S}
$$

Where: $\mathrm{E}(\mathrm{kWh})$ is the power consumption and $S\left(\mathrm{~m}^{-2}\right)$ the air-conditioned area

\section{Results and Discussions}

For the simulations, first, Yako lateritic bricks have been used. Then the thermo-physical characteristics of the lateritic blocks of the three (03) quarries were used to evaluate the monthly average temperatures in the building's premises. Figures 5 and 6 show the annual changes in air temperature and relative humidity in the different rooms of the building, respectively.

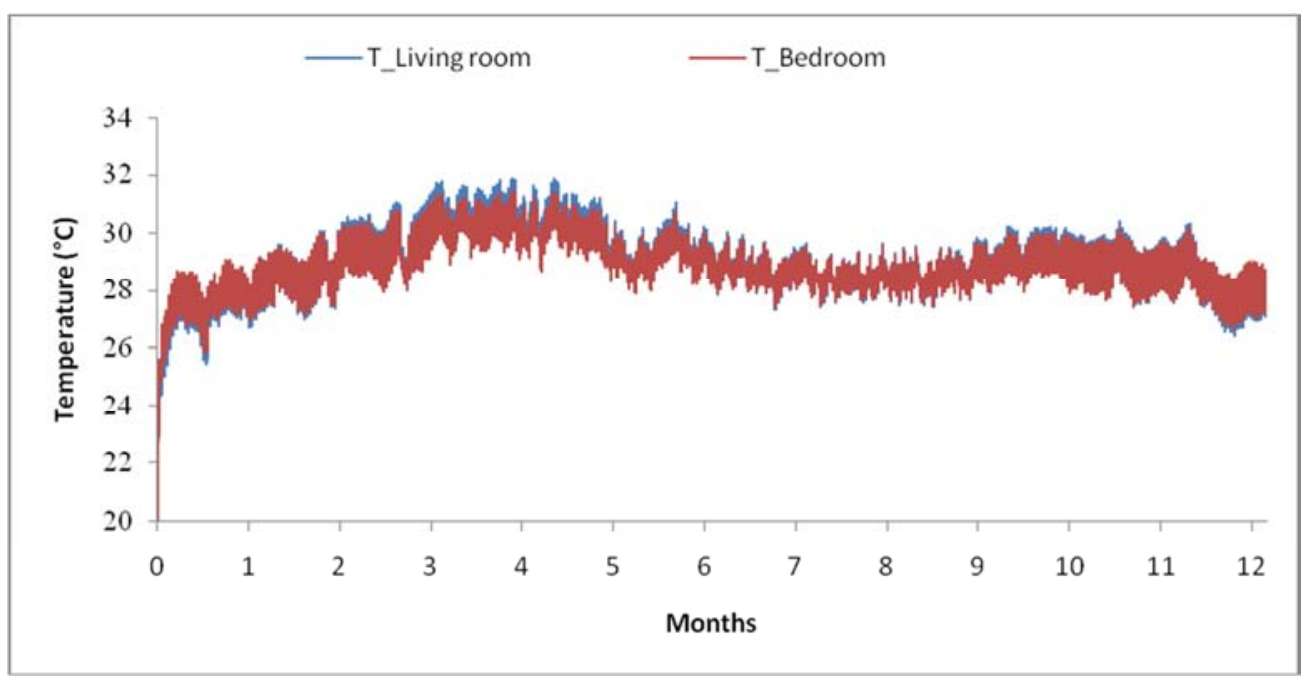

Figure 5. Annual evolution of hourly temperatures in the premises (Yako).

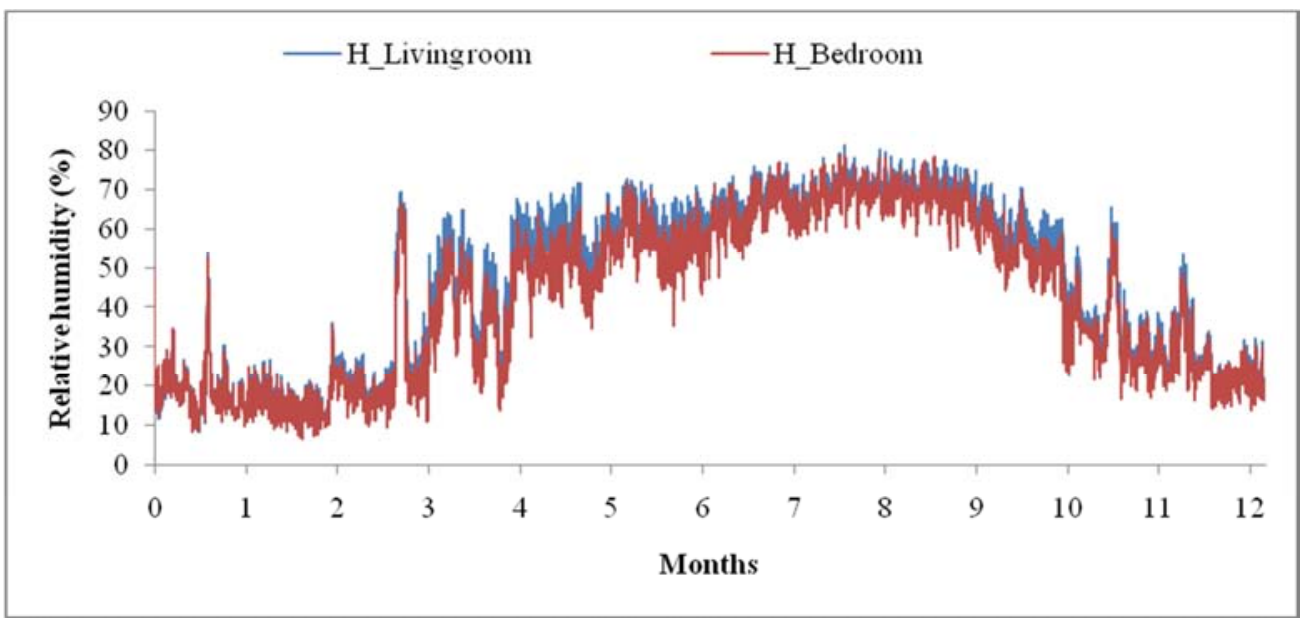

Figure 6. Annual evolution of the relative humidity per hour in the premises (Yako). 
It can be noted that there is thermal discomfort in these rooms during the hot seasons (March-May and OctoberNovember) with maximum internal temperature values reaching $31.6^{\circ} \mathrm{C}$ (Figure 5). This maximum temperature is much lower than what would be observed in a conventional building (about $34^{\circ} \mathrm{C}$ [18]), and is also lower than the temperature obtained by Safarova [19], which is $31.59^{\circ} \mathrm{C}$. During the other months of the year, internal temperatures are relatively low. As for relative humidity (Figure 6), these internal values are high during wintering due to high external relative humidity. High relative humidity values in rooms can be uncomfortable. However, this relative humidity can be evacuated from the building by good ventilation of the premises. Thus, the lowest humidity levels correspond to the warm seasons and the harmattan period (NovemberFebruary). These low indoor relative humidity values can be improved by the natural ventilation of the cooling humid air from the humidified green bins located near the low openings of the rooms.

Figures 7 and 8 show the evolution of air temperatures outside and inside the building premises.

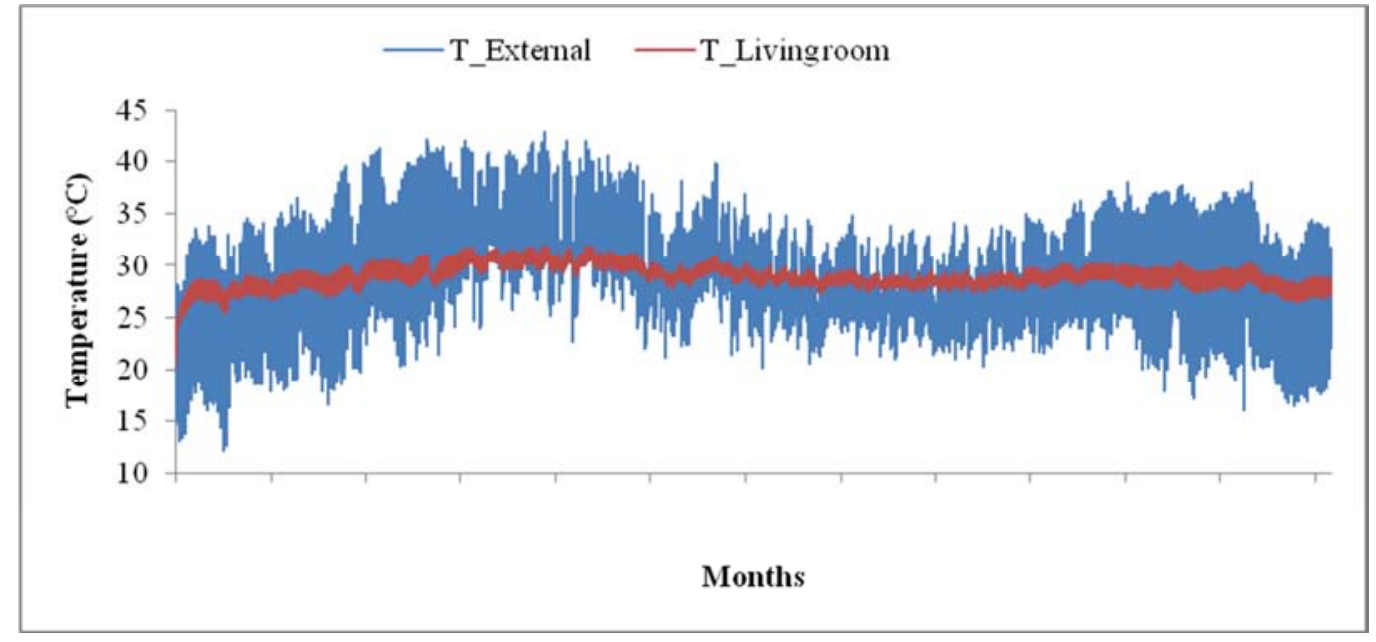

Figure 7. Annual evolution of hourly temperatures in the living room (Yako).

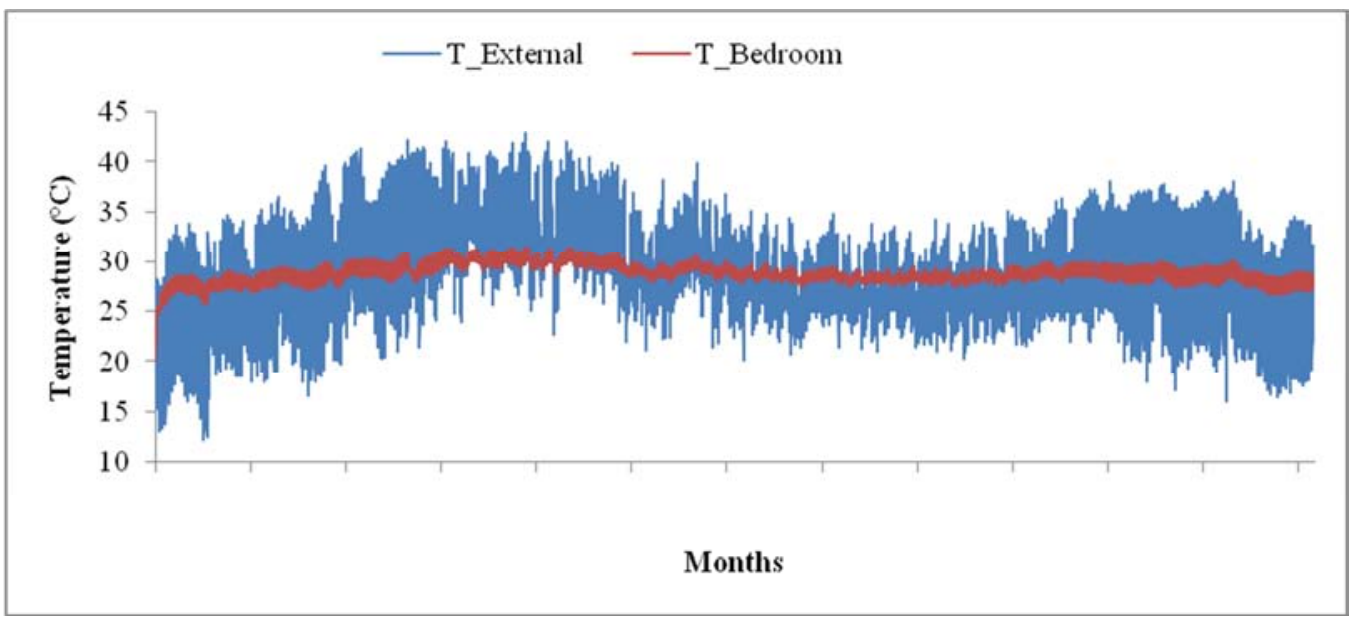

Figure 8. Annual evolution of hourly temperatures in the room (Yako).

It has been noticed that the amplitudes of the internal temperatures are highly damped (Figure 7). This reduction in amplitude is due to the good thermal performance of the characterized materials. The roof is ventilated by continuous openings separating the roof and ceiling, creating a ventilated attic above an insulating false ceiling. To ensure comfort, a trapdoor system can be used to evacuate, during the night, the heat stored during the day [18] Thermal comfort in the premises will be improved if the simulation is done with the thermo-physical properties of the Reo bricks, as they have the lowest thermal conductivity.

Figure 9 shows the changes in the monthly average air temperatures in the rooms (living room and bedroom) according to the type of materials. 


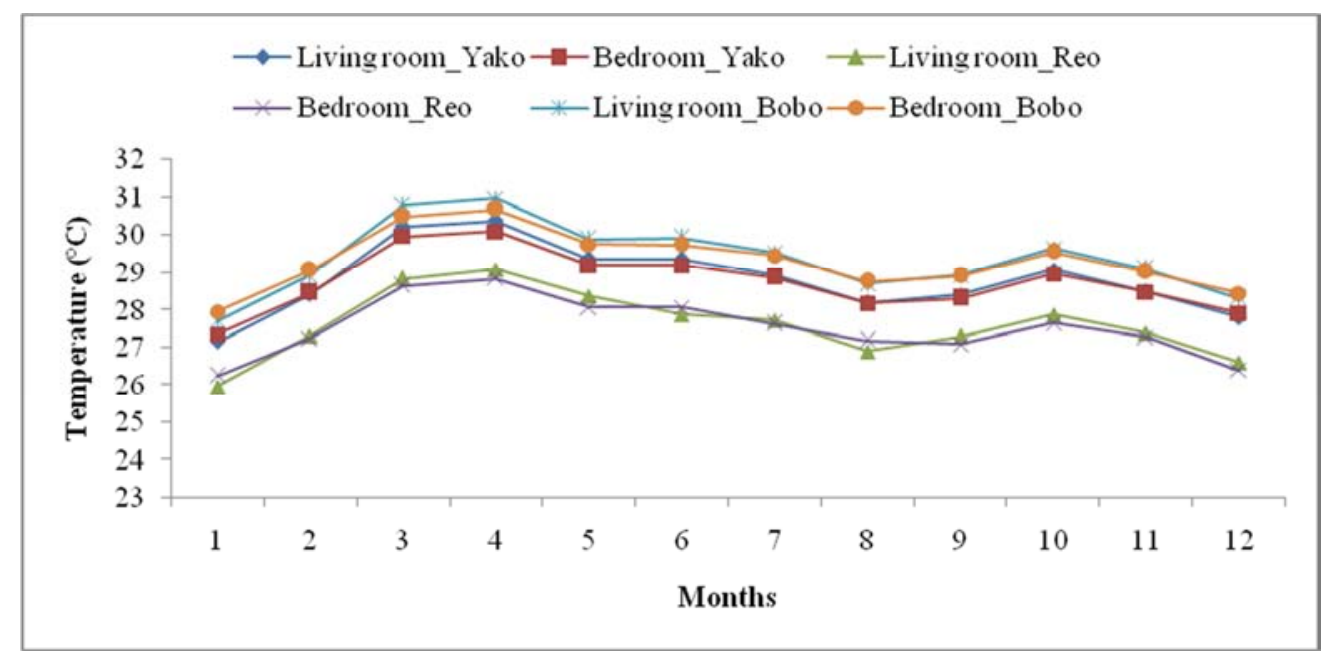

Figure 9. Annual evolution of hourly temperatures in the rooms according to the type of materials.

The internal temperature values (Figure 9) show that thermal comfort has been improved when the building walls are made of laterite blocks from Reo's quarry. This improvement is due to the fact that these blocks have better thermal performance. On the other hand, the use of lateritic bricks from the Bobo-Dioulasso quarry degrades the thermal comfort of the premises. The increase in internal temperature values (Figure 9) is related to the higher thermal conductivity values of these bricks; the use of Reo blocks allows the temperature to be reduced from 1.0 to $1.5^{\circ} \mathrm{C}$ compared to Yako's, but Bobo-Dioulasso's blocks increase the temperature by about $0.5^{\circ} \mathrm{C}$. Regardless of the type of lateritic block, the internal temperature of the building is much lower than that of a conventional building [18].

Table 2 shows the values of the damping factors and the thermal phase shift times of the building rooms as a function of the composition of the walls.
Table 2. Damping factors and thermal phase shift time.

\begin{tabular}{lllll}
\hline \multirow{2}{*}{ Type of wall } & \multicolumn{2}{l}{ Damping factor (\%) } & \multicolumn{2}{c}{ thermal phase shift time (h) } \\
\cline { 2 - 5 } & Living room & Bedroom & Living room & Bedroom \\
\hline BLT_Yako & 23,68 & 23,21 & 5 & 6 \\
BLT_Reo & 17,95 & 17,25 & 7 & 7 \\
BLT_Bobo & 26,68 & 26,53 & 5 & 5 \\
\hline
\end{tabular}

The values of thermal phase shifts for double face walls are higher than those obtained by Ouedraogo in his work on the thermal study of a building of type F4 in compressed earth blocks. There is a significant phase shift (minimum 5 hours) between the internal and external temperature peaks for the different wall compositions. The walls have damping factors of less than $27 \%$, so the temperatures passing through them (internal temperatures) are highly damped.

Figure 10 shows the values of the air conditioning loads of the rooms as a function of the composition of the building walls.

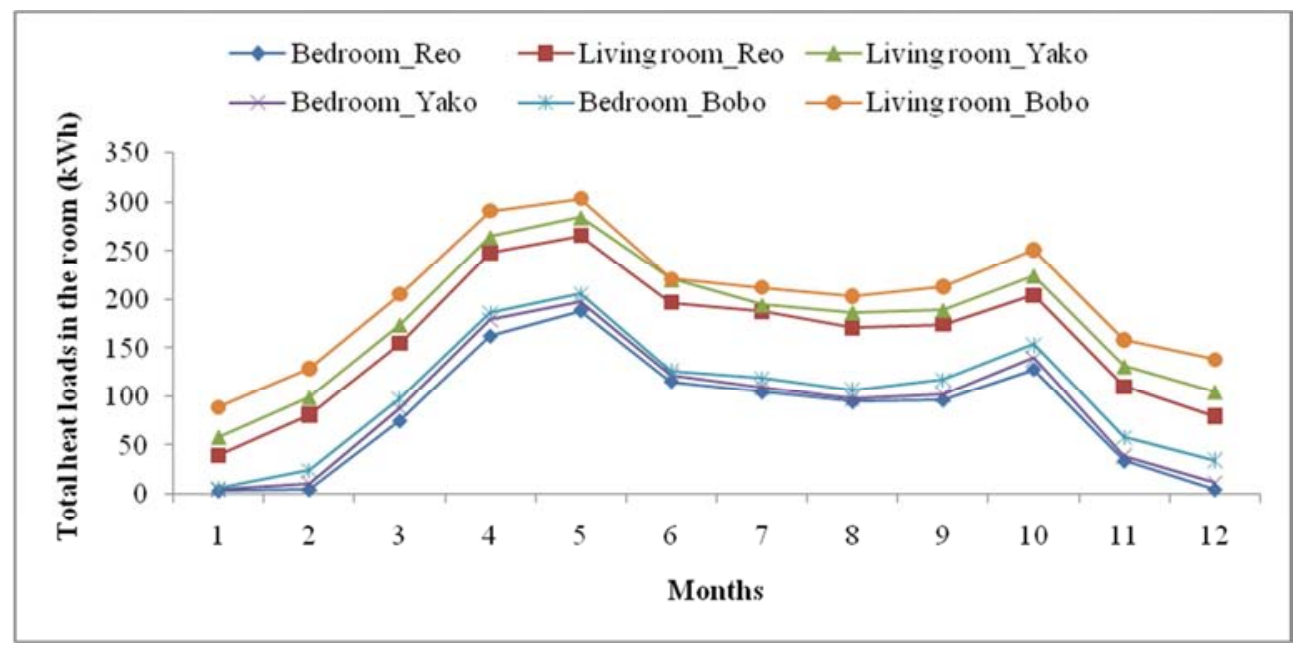

Figure 10. Values of room air conditioning loads.

The monthly consumption of air conditioners shows two (02) peaks corresponding to the two (02) hot seasons. During these periods, there is a very high consumption of air conditioners, with the maximum period being from April to
mid-May. This consumption is due to the high values of the outside air temperatures which increase the heat inside the room. The decrease in energy consumption between June and September and between November and February is due to the 
rainy season and the cold and dry period respectively. During these periods, outdoor air temperatures are low and heat

inputs into the room are minimal.

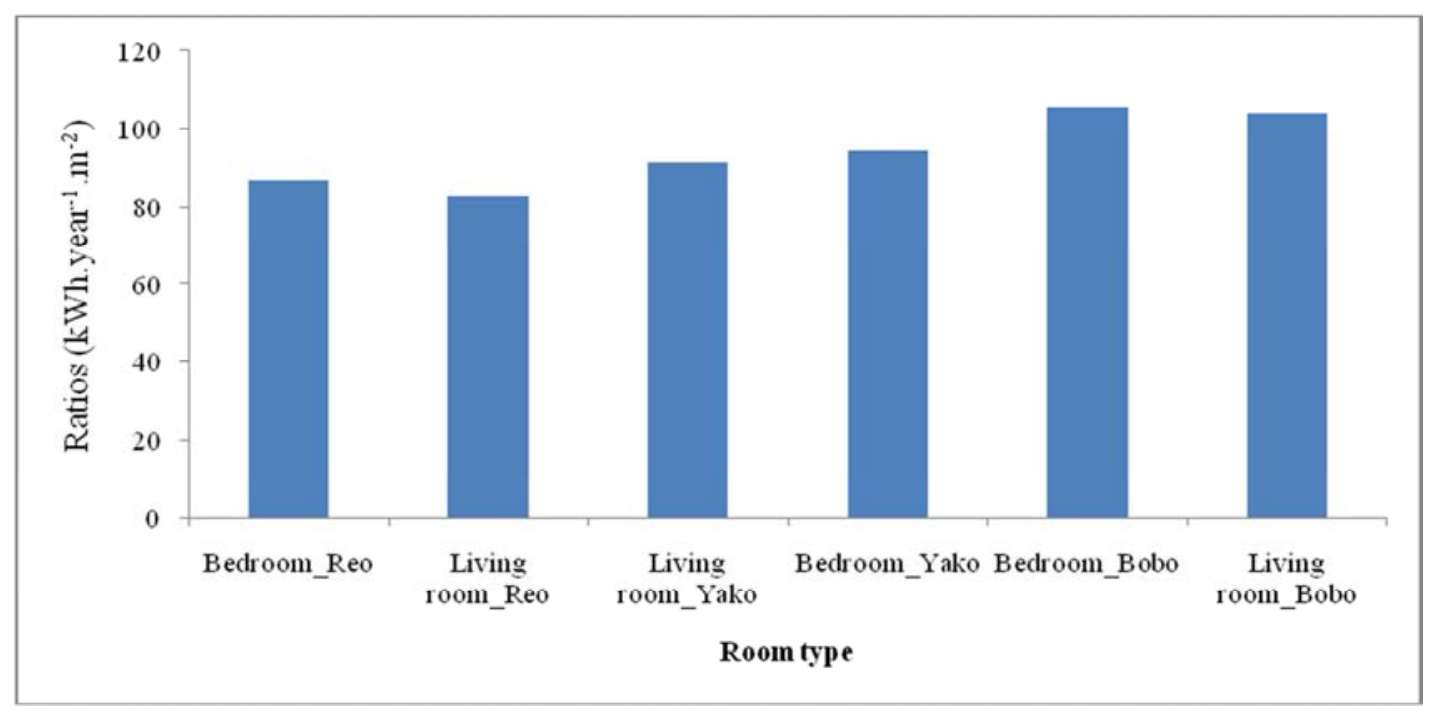

Figure 11. Annual energy consumption ratios of each room according to the nature of the walls.

The results in Figure 11, showing the energy consumption ratios, illustrate the building's performance. The values of these consumption ratios range from $82.65 \mathrm{kWh}$.year ${ }^{-1} . \mathrm{m}^{-}$ ${ }^{2}$ air-conditioned to $105.69 \mathrm{kWh} \cdot \mathrm{year}^{-1} \cdot \mathrm{m}^{-2}$ conditioned. All values are below $130 \mathrm{kWh} \cdot \mathrm{year}^{-1} \cdot \mathrm{m}^{-2}$ air-conditioned, the reference ratio for apartments proposed by the Ivorian energy quality code [2]. It is also noted that the values found in this study are very low compared to the energy consumption reference value of an apartment in a humid tropical climate (no reference in the literature for dry tropical climate) which is in the order of $160 \mathrm{kWh} \cdot \mathrm{year}^{-1} \cdot \mathrm{m}^{-2}$ [20]. Our building therefore has a very good energy performance.

The results obtained show that it is possible to do without active air conditioning in this type of housing while enjoying acceptable thermal comfort (building in BLT_Reo), anything that makes it possible to have a building that is energyefficient. Compaore et al [11] showed that increasing wall thickness contributes to a better thermal inertia of the habitat by improving the damping factor and thermal phase shift time. The option of using local materials having good thermo-physical properties and locally available makes it possible to decrease excessive costs in the construction of housing (building). This choice also creates employment in the localities where the quarries are located. To combine the useful with the pleasant, the promotion of these housing units in a context of self-help will improve the quality and harmony of our residential areas.

\section{Conclusion}

Modeling and simulation with TRNSYS software made it possible to determine the atmosphere (relative air temperatures and humidity) in the rooms of a typical building. The hourly air temperature values range from $25.5^{\circ} \mathrm{C}$ to $31.6^{\circ} \mathrm{C}$. From the results, a reduction in the temperature and relative humidity values of the internal air and a high damping of the internal thermal amplitudes have been observed. The temperature values showed that thermal comfort is not achieved in the rooms during the hot periods of the year for the building in BLT_Yako and BLT_BoboDioulasso. On the other hand, comfort is better in BLT_Reo premises. The values of damping factors, thermal phase shift times and energy consumption ratios show that the building has good energy and thermal performance. To improve this comfort, night ventilation and cooling humid air ventilation from the humidified green bins located near the low openings are available. Good ventilation of the premises by air mixers to obtain acceptable comfort temperatures is also suggested in accordance with the set temperatures $\left(26^{\circ} \mathrm{C}\right)$. Lighting recommendations may include the use of low-energy lamps and solar energy.

\section{References}

[1] Institute of Energy and the Environment of the Francophonie, (2006). PRISME Datasheets, Energy Efficiency Codes for Buildings, http://www.iepf.org/.

[2] Institute of Energy and the Environment of the Francophonie, (2002). Books PRISME, Energy Efficiency of Air Conditioning in Tropical Region, Volume 1: Design of New Buildings, 186 pages, www.iepf.org.

[3] General Directorate of Energy Energy Audit, and Domestic Energy Strategy (SED), (2003). Ministry of Energy and Mines of Burkina Faso.

[4] Edward Halawa, Amirhosein Ghaffarianhoseini, Ali Ghaffarianhoseini, Jeremy Trombley, Norhaslina Hassan, Mirza Baig, SafiahYusmahYusoff, Muhammad Azzam Ismail, (2018). A review on energy conscious designs of building façades in hot and humid climates: Lessons for (and from) Kuala Lumpur and Darwin. Renewable and Sustainable Energy Reviews, 82 (3) 2147-2161. 
[5] Seyedehzahra Mirrahimi, Mohd Farid Mohamed, Lim Chin Haw, Nik Lukman NikIbrahim, Wardah Fatimah Mohammad Yusoff, Ardalan Aflaki, (2016). The effect of building envelope on the thermal comfort and energy saving for highrise buildings in hot-humid climate. Renewable and Sustainable Energy Reviews, 53, 1508-1519.

[6] Zhengen Ren, Dong Chen, (2018). Modeling study of the impact of thermal comfort criteria on housing energy use in Australia. Applied Energy, 210, 152-166.

[7] Loyde V. de Abreu-Harbich, Victor L. A. Chaves, Maria Carolina G. O. Brandstetter, (2018). Evaluation of strategies that improve the thermal comfort and energy saving of a classroom of an institutional building in a tropical climate. Building and Environment, 135, 257-268.

[8] Trupti J. Dabe, Vinayak S. Adane, (2018). The impact of building profiles on the performance of daylight and indoor temperatures in low-rise residential building for the hot and dry climatic zones. Building and Environment, 140, 173-183.

[9] David Y. K. Toguyeni, Ousmane Coulibaly, Abdoulaye Ouedraogo, Jean Koulidiati, Yvan Dutilc, Daniel Rousse, (2012). Study of the influence of roof insulation involving local materials on cooling loads of houses built of clay and straw. Energy and Buildings, 50, 74-80.

[10] Compaore A., Ouedraogo B., Guengane H., Malbila E., Bathiebo D. J., (2017). Role of Local Building Materials on the Energy Behaviour of Habitats in Ouagadougou. IRA International Journal of Applied Sciences, 8 (2), 63-72.

[11] Abdoulaye Compaore, Boureima Dianda, Gilbert Nana, D. Joseph Bathiebo, Belkacem Zeghmati, Xavier Chesneau and Stéphane Abide, (2018). Modeling of Heat Transfer in a Habitat Built in Local Materials in Dry Tropical Climate. Physical Science International Journal, 7 (1): 1-11.

[12] Emmanuel Ouédraogo, Ousmane Coulibaly, B. Kossi Imbga, P. Florent Kiéno and Abdoulaye Ouédraogo, (2018). Experimental Study of the Thermo-physical Properties of
Lateritic Blocks Used in the Habitat in Dry Tropical Climate. Physical Science International Journal, 19 (2): 1-10.

[13] Lawane A., Vinai R., Pantet A., Thomassin J. H, (2011). Characterisation of laterite stone as building material in Burkina Faso. Scientific day 2IE.

[14] Abdou Lawane, Anne Pantet, Raffaele Vinai, Jean Hugues Thomassin, (2011). Geological and geomechanical study of the laterites of Dano (Burkina Faso) for a use in the habitat. The annals BTP.; $n^{\circ} 1 n^{\circ} 6$.

[15] Ousmane Coulibaly, Emmanuel Ouedraogo, Abdoulaye Ouedraogo et Jean Koulidiati, (2015). Determination of typical meteorological years used for thermal and energy simulation of buildings in ten cities of Burkina Faso. Afrique Science, 11 (6), 158-169.

[16] E. Ouedraogo, O. Coulibaly et A. Ouedraogo, (2012). Elaboration of a typical meteorological year for the city of Ouagadougou for study the energy performances of buildings, Revue des Energies Renouvelables, 15 (1), 77-90.

[17] Emmanuel Ouedraogo, (2015). Determination of basic climate data and characterization of compressed earth blocks for the study of thermal comfort in the building in dry tropical climate, $\mathrm{PhD}$ Thesis, University of Ouagadougou.

[18] O. Coulibaly; A. Ouedraogo; J. Koulidiati, P. Abadie; (2013). Thermal study of a double-wall bioclimatic building called NEWANGO: thermal inertia, comfort and energy consumption, Francophone energy link, 94, 80-86.

[19] Shokhida Safarova, (2017). Thermal Performance of 6 Star Rated Houses in the Hot and Humid Tropical Climate of Darwin. Procedia Engineering, 180, 510-519.

[20] Ousmane Coulibaly, (2011). Contribution to the elaboration of thermal and energy regulation of buildings in Burkina Faso: Multiparametric basic data and thermo-aeraulic modeling under CoDyBa and TRNSYS. PhD thesis, University of Ouagadougou. 